\title{
GMR
}

\section{Diagnostic values of microRNA-31 in peripheral blood mononuclear cells for pediatric pulmonary tuberculosis in Chinese patients}

\author{
J.X. Wang, J. Xu, Y.F. Han, Y.B. Zhu and W.J. Zhang \\ Infectious Diseases Branch, Laiwu City People's Hospital of Shandong Province, \\ Laiwu, Shandong, China \\ Corresponding author: J.X. Wang \\ E-mail: wangjixu1215@126.com \\ Genet. Mol. Res. 14 (4): 17235-17243 (2015) \\ Received August 9, 2015 \\ Accepted October 25, 2015 \\ Published December 16, 2015 \\ DOI http://dx.doi.org/10.4238/2015.December.16.23
}

ABSTRACT. We investigated the diagnostic values of microRNA-31 in peripheral blood mononuclear cells (PBMCs) for pediatric pulmonary tuberculosis in Chinese patients. Sixty-five children with TB were selected for this study, which was conducted at the Department of Infectious Diseases People's Hospital of Laiwu City between December 2013 and December 2014. Sixty healthy children, selected in parallel, served as the control group. Real-time PCR was used to detect miR-31 expression in PBMCs. Serum levels of IL-6, TNF- $\alpha, N F-K B$, and IFN- $\gamma$ was detected by ELISA. ROC curve was employed to evaluate the diagnostic value of miR31 in pediatric TB. Results show that expression of miRNA-31 in pediatric TB patients was significantly lower than that in normal children $(0.48 \pm 0.15$ vs $1.23 \pm 0.36, P<0.05)$. By contrast, serum levels of the innate immune response cytokines, IL-6, TNF- $\alpha$, NF-KB, and IFN- $\gamma$, were significantly higher in pediatric TB patients compared with normal children $(P<0.05)$. Furthermore, miRNA-31 expression was negatively correlated with serum levels of IL-6 $(t=69.91, P<0.001)$, TNF- $\alpha(t=10.96, P<0.001)$, NF-KB $(t=$ 39.94, $P<0.001)$, and IFN $-y(t=37.94, P<0.001)$. The cut-off threshold of miR-31 for pediatric TB diagnosis is 0.835 with a sensitivity of $98.5 \%$ and a 
specificity of $86.7 \%$. Therefore, miR-31 has the potential to be a diagnostic marker in pediatric TB patients.

Key words: miR-31; Tuberculosis; Peripheral blood mononuclear cells; IL-6; TNF- $\alpha$; NF-KB

\section{INTRODUCTION}

Pulmonary tuberculosis (TB) is a major infectious disease that is second only to human immunodeficiency virus (HIV) in terms of disease-related deaths (Shaler et al., 2012). It is estimated that one third of the world's total population is currently infected with Mycobacterium tuberculosis (MtB), the causative bacterium of TB. Furthermore, new TB cases are occurring at an alarming rate of 9 million per year, with approximately 1.5 million TB-related deaths per year worldwide. While MtB poses significant risk to human health, fortunately, only $5-10 \%$ of those infected develop the active form of the disease (Dalgic et al., 2011). According to the World Health Organization (WHO) estimates, one million children develop TB worldwide, accounting for $11 \%$ of total annual TB cases (Dalgic et al., 2011). In 2011, half a million children (0-14 years) developed TB, and 64,000 children died from the disease. Risk of TB infection in children is $2-5 \%$ in developing countries (Veedu et al., 2013). At-risk groups in children include those of lower socioeconomic status, being in an immunecompromised state, having a history of incarceration, or living in countries with high TB incidence (Yousef et al., 2013). The host immune response to MtB determines the clinical outcome in the early phase of infection. MtB is an intracellular pathogen that is phagocytosed by antigen-presenting cells such as lung parenchyma macrophages, alveolar macrophages, and dendritic cells in the lungs (Torun et al., 2014). Pediatric TB is often treated as a low-priority disease by national TB control programs owing to limited resources, which are reserved for sputum smear-positive cases that contribute to active TB transmission (Wang et al., 2013). Furthermore, diagnosis of pediatric TB is challenging, and children infected with TB are major reservoirs for adulthood tuberculosis and disease transmission (Bolursaz et al., 2014). Recent studies have focused on the role of microRNAs (miRs) as sensitive diagnostic markers in various diseases, including pediatric TB.

MiRs are short RNA molecules of 21-25 nt in length, and are important regulators of posttranscriptional gene expression. Upon binding to their target mRNAs, miRs either inhibit translation or promote mRNA degradation, thereby controlling protein synthesis (Spinelli et al., 2013). MiRs regulate diverse cellular processes such as cell differentiation, proliferation, organ development and act as biomarkers for infectious diseases (Fu et al., 2011). Several miRs have been found to regulate differentiation and function of $T$ cells, and have critical roles in regulating macrophages, dendritic cells, and innate functions of NK cells (Liu et al., 2011; Harapan et al., 2013). For example, miRNA-155 is essential for T cell-mediated Helicobacter pylori infection, and miR-147 attenuates TLR-induced inflammatory responses (Yi et al., 2012). In addition, Wu et al. found that miR-155 and $\mathrm{miR}-155^{*}$ are potential diagnostic markers that are up-regulated during immune challenge with MtB antigens (Wu et al., 2012). Liu et al. also demonstrated that miR-582-5p plays an essential role in regulating anti-MtB directed immune responses by inhibiting monocyte apoptosis as well as down-regulating FOXO1 expression (Liu et al., 2013).

In this study, we investigated the diagnostic values of microRNA-31 in peripheral blood mononuclear cells for pediatric pulmonary tuberculosis patients in a Chinese population. The correlation between miR-31 expression and serum levels of IL-6, TNF- $\alpha, N F-k B$, and IFN- $\gamma$ was determined to understand the pathways involved in TB development. 


\section{MATERIAL AND METHODS}

\section{Subjects}

Sixty-five pediatric TB patients were enrolled for the study at the Department of Infectious Diseases in People's Hospital of Laiwu City, Shandong Province, between December 2013 and December 2014. The TB group consisted of 38 males and 27 females and ranged between 1 and 10 years of age. Among these, 21 and 44 patients were under and over the age of 3, respectively. All pediatric TB subjects met the "Clinical diagnostic criteria and treatment plan for pediatric tuberculosis" (Pan et al., 2014). Sixty healthy children were also recruited within the same timeperiod, and were defined as the control group. The control group consisted of 35 males and 25 females, and ranged between 2 and 11 years of age. Among the healthy subjects, 20 and 40 were under and over the age of 3 , respectively. The control group had no history of recent exposure to TB, other viral infections, and disease of the vital organs such as heart, liver, lung, and kidney. There were no significant differences in age and gender between the TB group and the control group $(P>0.05)$. This study was approved by the Ethics Committee of People's Hospital of Laiwu City, Shandong Province, and parents of all the children in this study signed written informed consents. This study conformed to the Declaration of Helsinki.

\section{PBMC collection and RNA extraction and detection}

Peripheral venous blood $(2 \mathrm{~mL})$ from each subject was collected and placed into tubes containing the anticoagulant EDTA. All plasticware was RNase-free. The blood was briefly mixed, and transferred into $15 \mathrm{~mL}$ centrifuge tubes. Next, $1 \mathrm{X}$ erythrocyte lysis buffer $(6 \mathrm{~mL})$ was added to the tubes, the contents were mixed and placed on ice for $5 \mathrm{~min}$. The tubes were centrifuged at $3000 \mathrm{rpm}$ for $5 \mathrm{~min}$, and the supernatant was carefully aspirated and discarded. If the red cell mass remained at the bottom of the tube, indicating insufficient lysis, $1 \mathrm{~mL} 1 \mathrm{X}$ erythrocyte lysis buffer was added again, mixed and centrifuged to isolate the white cell pellet, which was defined as the PBMC. Following isolation of the PBMC, $1 \mathrm{~mL}$ Trizol reagent was added and mixed on ice for 5 min. Chloroform $(200 \mu \mathrm{L})$ was then added, mixed, and the samples were left on ice to resolved the two phases. Following this, samples were centrifuged for $15 \mathrm{~min}$ at $4^{\circ} \mathrm{C}$ and $12,000 \mathrm{rpm}$. Three layers were visualized: the upper layer (aqueous phase) contained RNA, the intermediate layer contained proteins and DNA, and the lower layer consisted of the organic phase. The supernatant $(550 \mu \mathrm{L})$ was carefully transferred to a $1.5 \mathrm{~mL}$ EP tubes and $550 \mu \mathrm{L}$ isopropanol was added. The sample was mixed and incubated at $-20^{\circ} \mathrm{C}$ for $20 \mathrm{~min}$. After centrifuging at for $15 \mathrm{~min}$ at 12,000 rpm and $4^{\circ} \mathrm{C}$, visible RNA pellet was observed at the bottom of the tube. The isolated total RNA was dissolved in $50 \mu \mathrm{L}$ diethylpyrocarbonate-treated water at $55^{\circ} \mathrm{C}$ for $5 \mathrm{~min}$. Nano-Drop $1000 \mathrm{UV}$ vis spectrophotometer was used to detect RNA concentration and purity. Purity was indicated by OD260/OD280, and a value between 1.8 and 2.1 was regarded as acceptable for the study.

\section{Real-time PCR}

The miScript Reverse Transcription kit (Qiagen) was used for cDNA synthesis. Quantitative PCR was performed using the miScript SYBR Green PCR kit (Qiagen), and was conducted on the Applied Biosystems 7900HT Sequence Detection System. The reaction conditions were as follows: 
initial denaturation at $94^{\circ} \mathrm{C}$ for $2 \mathrm{~min}, 40$ cycles of denaturation at $94^{\circ} \mathrm{C}$ for $20 \mathrm{~s}$, annealing at $60^{\circ} \mathrm{C}$ for $34 \mathrm{~s}$, and extension at $95^{\circ} \mathrm{C}$ for $15 \mathrm{~s}$, followed by $60^{\circ} \mathrm{C}$ for $15 \mathrm{~s}$ and $95^{\circ} \mathrm{C}$ for $15 \mathrm{~s}$. Primers were synthesized by Shanghai Biotechnology Co., Ltd. Sequences of the primers used are as follows: $\mathrm{miR}$ 31: forward: 5'-AGGCAAGATGCTGGCATAG-3', reverse: 5'-AUUACGUUCUACGACCGUAUC-3'; U6: forward: 5'-TTCGTGAAGCGTTCCATATTTT3', reverse: 5'-GTGCAGGGTCCGAGGT-3'. U6 was used as internal control, and qPCR was formed in triplicates. Relative quantitation method was used to detect miR-31 expression in both the TB group and the control group. The relative miR-31 expression was calculated as $2^{-\Delta \Delta C t}$. As shown in Figure $1 A$ and $B$, the peak value of the melting curves for miR-31 and U6 was defined as Tm, which represents the temperature at which $50 \%$ of the double-stranded DNA denatures. It was determined that $\mathrm{Tm}$ of $\mathrm{miR}-31$ was $79^{\circ}-80^{\circ} \mathrm{C}$, and as illustrated by the single melting peak, the primers used were specific for said gene. The $x$-axis in the amplification curve represents fluorescence intensity, and the $y$-axis represents the number of PCR cycles. The intersection point of the green line and the amplification curve denotes the $\mathrm{Ct}$ value, i.e., the cycle number at which fluorescence intensity reached the threshold value.
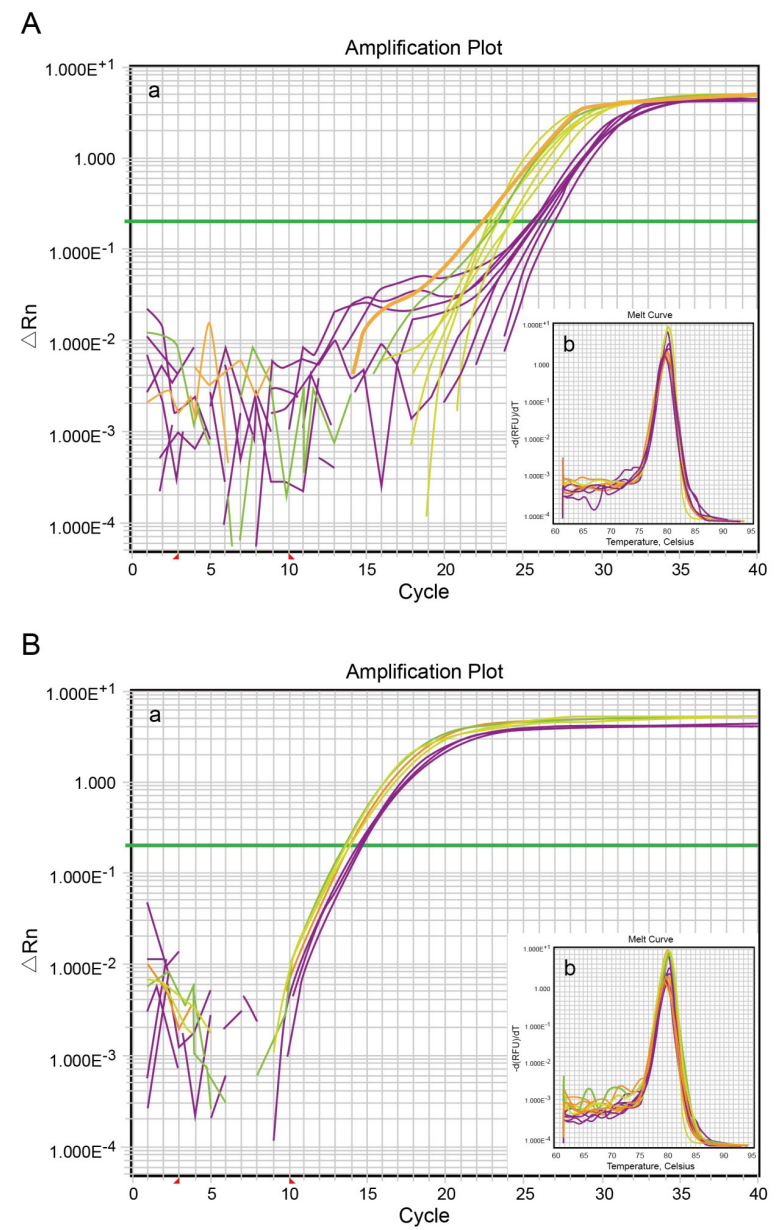

Figure 1. Amplification plot (a) and melting curve (b) of (A) miRNA-31 and (B) U6 assay. 


\section{Serum IL-6, TNF- $\alpha$, NF-kB and IFN-ץ levels detection}

Serum levels of IL-6, TNF- $\alpha, N F-k B$, and IFN- $\gamma$ were detected by Enzyme-linked immunoassay (ELISA). Peripheral venous blood $(1 \mathrm{~mL})$ from each subject was collected and centrifuged at $3000 \mathrm{rpm}$ for $10 \mathrm{~min}$. The supernatant was collected in EP tube and stored at $-70^{\circ} \mathrm{C}$. IL-6, TNF- $\alpha, N F-K B$ and IFN-y detection kits were purchased from Thermo Electron Corporation (US), and assays were performed according to manufacturer protocols. Briefly, $100 \mu \mathrm{L}$ standards, controls, and test samples at different concentrations were added to the wells of a microplate. The plate was sealed and incubated at room temperature for 2 hours. Next, wells were washed four times with $200 \mu \mathrm{L}$ cleaning mixture using an automatic washer. All samples were incubated with $200 \mu \mathrm{L}$ horseradish peroxidase (HRP) $(200 \mu \mathrm{L})$ at room temperature for 2 hours. Following standard washing procedures, chromogenic substrate $(200 \mu \mathrm{L})$ was added to the samples and incubated for $30 \mathrm{~min}$ at room temperature in the dark. Finally, $50 \mu \mathrm{L}$ of stop solution was added in each well, and absorbance at $450 \mathrm{~nm}$ was measured using a microplate reader within 30 minutes of reaction termination. All OD values were normalized to control values. A standard curve was plotted with concentration of standards as the $x$-axis and the OD value as the $y$-axis. Concentrations of individual samples were extrapolated from the standard curve.

\section{Statistical analysis}

The SPSS18.0 software was used for data processing. Measurement data was presented as mean \pm standard deviation. The $t$-test was used for statistical analysis of measured data. Pearson's correlation method was used for correlation analysis. Receiver operating characteristic (ROC) curve was used to evaluate the diagnostic value of miR-31 expression in pediatric TB. P < 0.05 represents statistical significant difference.

\section{RESULTS}

\section{Comparison of miR-31 expression in the TB group and the control group}

Expression of miR-31 in the TB group was significantly lower than the control group $(0.48$ \pm 0.15 vs $1.23 \pm 0.36, P<0.05$ ) (Figure 2). However, miR-31 showed no significant differences with age, gender, and clinical classification of pediatric TB (all P > 0.05) (Table 1).

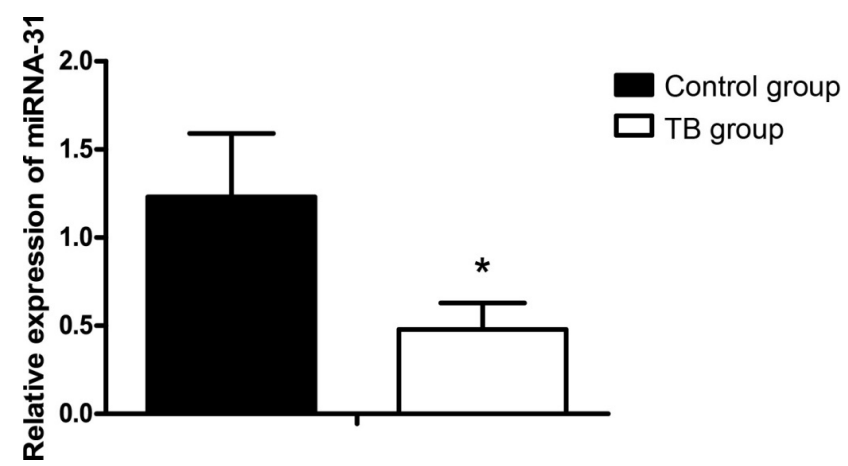

Figure 2. RT-PCR detection of miR-31 expression in the control TB group. *Compared with the control group, $\mathrm{P}<0.05$. 


\begin{tabular}{lccc}
\multicolumn{2}{l}{ Table 1. Relationship between miR-31 expression and clinical features of TB patients. } & P value \\
\hline Parameter & Cases & miR-31 expression & 0.621 \\
\hline Age (years) & & & \\
$<3$ & 21 & $0.48 \pm 0.16$ & 0.254 \\
$\geq 3$ & 44 & $0.46 \pm 0.13$ & \\
Gender & & $0.49 \pm 0.16$ & 0.155 \\
$\quad$ Male & 38 & $0.45 \pm 0.12$ & \\
$\quad$ Female & 27 & $0.46 \pm 0.16$ & $0.57 \pm 0.18$ \\
Clinical classification & 50 & $0.54 \pm 0.22$ & \\
$\quad$ Primary pulmonary tuberculosis & 8 &
\end{tabular}

\section{Comparison of serum IL-6, TNF- $\alpha$, NF-kB, and IFN- $\gamma$ levels in the TB and control groups}

Serum levels of IL-6, TNF- $\alpha, N F-k B$, and IFN- $\gamma$ were significantly higher in the TB group as compared with the control group (IL-6: $0.87 \pm 0.04$ vs $0.42 \pm 0.03, t=69.91, P<0.001$; TNF- $\alpha$ : $2.13 \pm 0.82$ vs $0.96 \pm 0.25, \mathrm{t}=10.96, \mathrm{P}<0.001 ; \mathrm{NF}-\mathrm{kB}: 1.18 \pm 0.15$ vs $0.33 \pm 0.08, \mathrm{t}=39.94, \mathrm{P}<$ 0.001 ; IFN-y: $116.21 \pm 4.96$ vs $90.78 \pm 2.06, \mathrm{t}=37.94, \mathrm{P}<0.001)$ (Table 2 ).

\begin{tabular}{|c|c|c|c|c|}
\hline & Control group & TB group & $t$ & $\mathrm{P}$ \\
\hline IL-6 (pg/mL) & $0.42 \pm 0.03$ & $0.87 \pm 0.04$ & 69.91 & $<0.001$ \\
\hline TNF- $\alpha(n g / m L)$ & $0.96 \pm 0.25$ & $2.13 \pm 0.82$ & 10.96 & $<0.001$ \\
\hline NF-KB (ng/mL) & $0.33 \pm 0.08$ & $1.18 \pm 0.15$ & 39.94 & $<0.001$ \\
\hline IFN-ץ (pg/mL) & $90.78 \pm 2.06$ & $116.21 \pm 4.96$ & 37.94 & $<0.001$ \\
\hline
\end{tabular}

\section{Correlation analysis}

Significant negative correlation was found between miR-31 expression and serum levels of IL-6, TNF- $\alpha$, NF-kB, and IFN - $\mathrm{Y}$ (IL-6: $r=-0.834, \mathrm{P}<0.001$; TNF- $\alpha$ : $r=-0.941, \mathrm{P}<0.001$; NF-KB: $r=-0.926, P<0.001$; IFN-y: $r=-0.866, P<0.001$ ) (Figure $3 A, B, C$ and $D$ ).
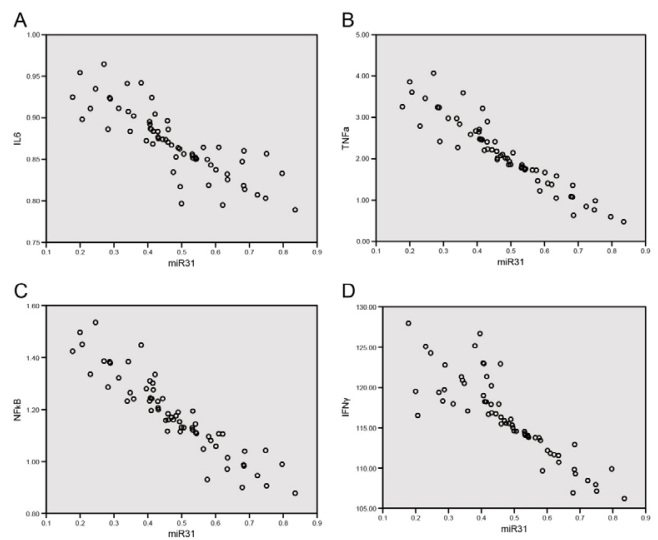

Figure 3. Negative correlation between miR-31 expression and (A) IL-6, (B) TNF- $\alpha$, (C) NF-KB, and (D) IFN-y in children with TB. 


\section{Diagnostic value of miR-31 expression levels in pediatric TB}

The area under the ROC curve (AUC) was $0.966(95 \% \mathrm{Cl}=0.934-0.998)$. MiR-31 expression at a cut-off value of 0.835 in pediatric TB patients was clearly distinguishable from the healthy controls. With this cutoff value, sensitivity and specificity of the miR-31 expression for pediatric TB were 98.5 and $86.7 \%$, respectively, indicating its high diagnostic value (Figure 4).

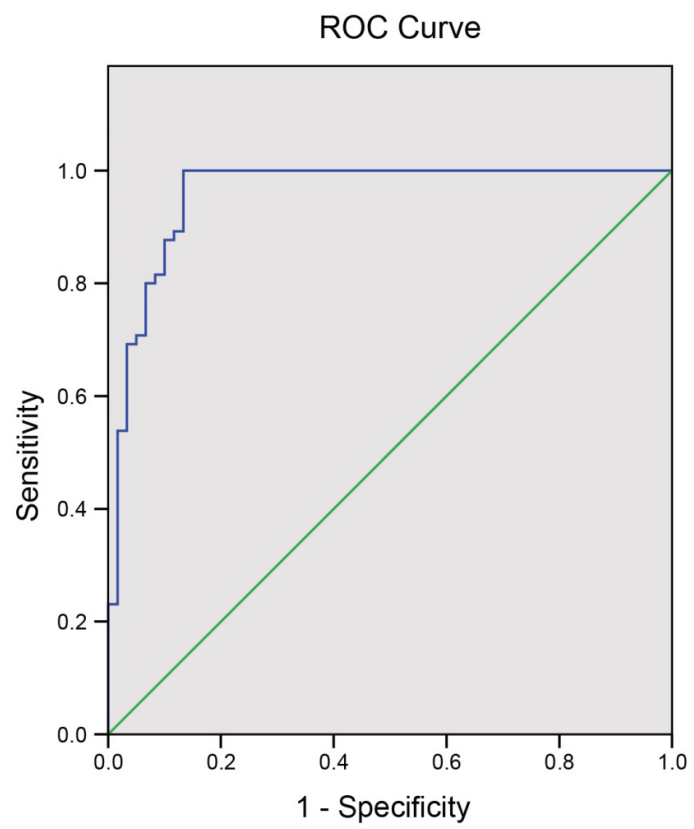

Figure 4. Receiver operating characteristic (ROC) plot of miR-31 for assessment of accuracy.

\section{DISCUSSION}

Our study examined the role of miR-31 in the development of pediatric TB. MtB can cause TB, and the host cell-mediated immune responses play a fundamental role against MtB infection (Wu et al., 2012). Many studies support the view that miRs have important roles in viral replication and can control viral infections including retroviruses, herpes viruses and small DNA viruses (Ha, 2011). Moreover, miRNAs are essential in both adaptive and innate immunity by influencing immune cell differentiation and mediating their immunological functions (Spinelli et al., 2013). For example, miR-31 regulates the expression of multiple pro-metastatic genes, and inhibits cellular processes involved in tumor invasion and metastasis (Valastyan et al., 2009; Schmittgen, 2010). In addition, miR-31 inhibits noncanonical NF-kB pathways by targeting NF-kB inducing kinase, and the loss of miR-31 triggers oncogenic signaling (Yamagishi et al., 2012). Furthermore, miR-31 also participates in inflammatory responses, and it is found that TNF- $\alpha$ enhances miR-31 expression in endothelial cells to suppress E-selectin, a endothelial adhesion molecule that triggers inflammatory signaling (Valastyan and Weinberg, 2010). However, few studies have addressed the role of miR31 in infectious diseases, especially pediatric TB. 
Our result showed that expression of miR-31 in pediatric TB patients was significantly lower as compared to the control group, suggesting the miR-31 found in PBMC may have protective roles. Consistent with this observation, miR-31 expression at 0.835 was the clear cut-off value to distinguish pediatric TB patients from healthy controls. In terms of diagnostics, sensitivity and specificity of miR-31 expression for pediatric TB were 98.5 and $86.7 \%$, respectively, suggesting high diagnostic potential for miR-31. Due to the immature nature of the immune system in neonates and children under the age of 3 , diagnosis of TB based on immune responses is difficult. Children, unlike the adult patients, generally do not mount a measurable immune response to MtB. Thus, mi-31 offers a sensitive and specific alternative for TB detection in children. Bioinformatic analyses showed that 59 miRs were down-regulated and 33 miRs were up-regulated in the TB serum compared to normal control serum, suggesting potential roles for miRs in active TB infections (Fu et al., 2011). Qi et al. (2012) also found that levels of miR-361-5p, miR-889, and miR-576$3 p$ distinguished TB patients from healthy controls with moderate sensitivity and specificity (AUC range, 0.711-0.848).

Another aim of our study focused on the mechanism of miR-31 during the development of pediatric TB. Serum levels of IL-6, TNF- $\alpha, N F-K B$ and IFN- $\gamma$ were found to be significantly higher in the TB group compared with the control group. In addition, expression of miR-31 expression was negatively correlated with serum levels of the innate immunity cytokines IL-6, TNF- $\alpha$, NF$\mathrm{KB}$, and IFN-y. IL-6 is secreted by Toll-like receptor 2-expressing cells during early MtB infection, and is involved in anti-tuberculosis immunity (Feng et al., 2014). TNF- $\alpha$ increases the capacity of macrophages to phagocytose and stimulates macrophages apoptosis, which leads to increased presentation of mycobacterial antigens by dendritic cells (Cavalcanti et al., 2012). Infection of pulmonary epithelial cells with MtB may indirectly lead to NF-kB activation, resulting in IL-1 release and activation of the classical NF-kB pathway (Bonizzi and Karin, 2004). IFN- $\gamma$ induces autophagy in mycobacteria-infected cells, which is associated with protection against MtB (Dutta et al., 2012).

Taken together, miR-31 expression in PBMC is down-regulated in children with $\mathrm{TB}$, and could be a potential biomarker for TB diagnosis. Furthermore, miR-31 expression levels negatively correlate with serum levels of innate immune cytokines, suggesting that miR-31 may play a role in early immune response against MtB in pediatric TB patients.

\section{Conflicts of interest}

The authors declare no conflict of interest.

\section{ACKNOWLEDGMENTS}

We would like to thank our researchers for their hard work and the reviewers for their valuable advice.

\section{REFERENCES}

Bolursaz MR, Mehrian P, Aghahosseini F, Lotfian F, et al. (2014). Evaluation of the relationship between smear positivity and high-resolution CT findings in children with pulmonary tuberculosis. Pol. J. Radiol. 79: 120-125.

Bonizzi G and Karin M (2004). The two NF-kappaB activation pathways and their role in innate and adaptive immunity. Trends Immunol. 25: 280-288.

Cavalcanti YV, Brelaz MC, Neves JK, Ferraz JC, et al. (2012). Role of TNF-Alpha, IFN-Gamma, and IL-10 in the Development of Pulmonary Tuberculosis. Pulm. Med. 2012: 745483. 
Dalgic N, Tekin D, Kayaalti Z, Cakir E, et al. (2011). Relationship between toll-like receptor 8 gene polymorphisms and pediatric pulmonary tuberculosis. Dis. Markers 31: 33-38.

Dutta RK, Kathania M, Raje M and Majumdar S (2012). IL-6 inhibits IFN-gamma induced autophagy in Mycobacterium tuberculosis H37Rv infected macrophages. Int. J. Biochem. Cell Biol. 44: 942-954.

Feng FM, Liu XX, Sun YH, Zhang P, et al. (2014). Independent and joint effects of the IL-6 and IL-10 gene polymorphisms in pulmonary tuberculosis among the Chinese Han population. Genet. Mol. Res. 13: 7766-7772.

Fu Y, Yi Z, Wu X, Li J, et al. (2011). Circulating microRNAs in patients with active pulmonary tuberculosis. J. Clin. Microbiol. 49: 4246-4251.

Ha TY (2011). MicroRNAs in Human Diseases: From Lung, Liver and Kidney Diseases to Infectious Disease, Sickle Cell Disease and Endometrium Disease. Immune Netw. 11: 309-323.

Harapan H, Fitra F, Ichsan I, Mulyadi M, et al. (2013). The roles of microRNAs on tuberculosis infection: meaning or myth? Tuberculosis 93: 596-605.

Liu Y, Wang X, Jiang J, Cao Z, et al. (2011). Modulation of T cell cytokine production by miR-144* with elevated expression in patients with pulmonary tuberculosis. Mol. Immunol. 48: 1084-1090.

Liu Y, Jiang J, Wang X, Zhai F, et al. (2013). miR-582-5p is upregulated in patients with active tuberculosis and inhibits apoptosis of monocytes by targeting FOX01. PLoS One 8: e78381.

Pan JH, Pan JH and Zhang X (2014). Recent advances in the diagnosis and treatment of childhood tuberculosis. Zhongguo Dang Dai Er Ke Za Zhi 16: 218-224.

Qi Y, Cui L, Ge Y, Shi Z, et al. (2012). Altered serum microRNAs as biomarkers for the early diagnosis of pulmonary tuberculosis infection. BMC Infect. Dis. 12: 384.

Schmittgen TD (2010). miR-31: a master regulator of metastasis? Future Oncol. 6: 17-20.

Shaler CR, Horvath C, Lai R and Xing Z (2012). Understanding delayed T-cell priming, lung recruitment, and airway luminal T-cell responses in host defense against pulmonary tuberculosis. Clin. Dev. Immunol. 2012: 628293.

Spinelli SV, Diaz A, D’Attilio L, Marchesini MM, et al. (2013). Altered microRNA expression levels in mononuclear cells of patients with pulmonary and pleural tuberculosis and their relation with components of the immune response. Mol. Immunol. 53: 265-269.

Torun E, Gedik AH, Cakir E, Umutoglu T, et al. (2014). Serum paraoxonase 1 activity and oxidative stress in pediatric patients with pulmonary tuberculosis. Med. Princ. Pract. 23: 426-431.

Valastyan S and Weinberg RA (2010). miR-31: a crucial overseer of tumor metastasis and other emerging roles. Cell Cycle 9: 2124-2129.

Valastyan S, Reinhardt F, Benaich N, Calogrias D, et al. (2009). A pleiotropically acting microRNA, miR-31, inhibits breast cancer metastasis. Cell 137: 1032-1046.

Veedu PT, Bhalla AS, Vishnubhatla S, Kabra SK, et al. (2013). Pediatric vs adult pulmonary tuberculosis: A retrospective computed tomography study. World J. Clin. Pediatr. 2: 70-76.

Wang X, Wu Y, Zhang K, Guan C, et al. (2013). Value of real-time polymerase chain reaction in bronchoalveolar lavage fluid for diagnosis of pediatric pulmonary tuberculosis. Braz. J. Infect. Dis. 17: 718-719.

Wu J, Lu C, Diao N, Zhang S, et al. (2012). Analysis of microRNA expression profiling identifies miR-155 and miR-155* as potential diagnostic markers for active tuberculosis: a preliminary study. Hum. Immunol. 73: 31-37.

Yamagishi M, Nakano K, Miyake A, Yamochi T, et al. (2012). Polycomb-mediated loss of miR-31 activates NIK-dependent NFkappaB pathway in adult T cell leukemia and other cancers. Cancer Cell 21: 121-135.

Yi Z, Fu Y, Ji R, Li R, et al. (2012). Altered microRNA signatures in sputum of patients with active pulmonary tuberculosis. PLoS One 7: e43184.

Yousef N, Hasan RA and Abuhammour W (2013). Pulmonary tuberculosis outbreak in a pediatric population. Clin. Pediatr. 52: 589-592. 